\title{
Effects of the Mixed Mu/Kappa Opioid Nalbuphine on Cocaine-Induced Changes in Subjective and Cardiovascular Responses in Men
}

\author{
Nancy K Mello*,', Jack H Mendelson', Michelle B Sholar', Maria Jaszyna-Gasior', Nathalie Goletiani' and \\ Arthur J Siegel' \\ 'Alcohol and Drug Abuse Research Center, McLean Hospital-Harvard Medical School, Belmont, MA, USA
}

Kappa opioid agonists functionally antagonize some abuse-related and locomotor effects of cocaine, and reduce cocaine selfadministration by rhesus monkeys. We compared the cardiovascular and subjective effects of acute doses of the mu/kappa opioid nalbuphine alone $(5 \mathrm{mg} / 70 \mathrm{~kg}$, intravenous (i.v.)), with cocaine alone $(0.2 \mathrm{mg} / \mathrm{kg}$, i.v. $)$, and with nalbuphine + cocaine in combination, under placebo-controlled, double-blind conditions. Subjects met American Psychiatric Association Diagnostic and Statistical Manual (DSM-IV) criteria for current cocaine abuse. Nalbuphine serum levels exceeded $50 \mathrm{ng} / \mathrm{ml}$ within 10 min after injection, and cocaine plasma levels exceeded $130 \mathrm{ng} / \mathrm{ml}$ within 4 min. Cocaine's pharmacokinetic profile did not change after concurrent nalbuphine administration. The nalbuphine + cocaine combination was safe and without synergistic effects on heart rate and systolic or diastolic blood pressure. Moreover, the addition of cocaine did not increase the subjective effects of nalbuphine. Visual Analog Scale (VAS) ratings of High, Euphoria, Stimulated, and Good Effect were equivalent after nalbuphine + cocaine and nalbuphine alone, and both were significantly higher than after cocaine alone (area under the curve analysis) ( $p<0.05-0.01$ ). Peak VAS ratings of High, Stimulated, Good Effect, and Drug Effect were also significantly higher after nalbuphine + cocaine than after cocaine alone $(p<0.0 \mathrm{I})$. Addiction Research Center Inventory (ARCl) scores were equivalent for nalbuphine + cocaine and nalbuphine alone, but the PCAG, MBG, and amphetamine scores were significantly higher after both nalbuphine + cocaine and nalbuphine alone than after cocaine alone $(p<0.0 \mathrm{I}-$ 0.003). Thus, there were no additive interactions between nalbuphine and cocaine on cardiovascular, subjective, or drug level measures after acute administration.

Neuropsychopharmacology (2005) 30, 6I8-632, advance online publication, I 5 December 2004; doi: I0. I038/sj.npp. I 30063 I

Keywords: cocaine; nalbuphine; cocaine + nalbuphine; cocaine abuse; cardiovascular measures; subjective effects

\section{INTRODUCTION}

Cocaine abuse continues to be a major public health problem, and the adverse medical consequences of cocaine abuse and dependence contribute to the social and economic costs (Novick et al, 1997; Mendelson and Mello, 2004). As yet, no effective pharmacotherapies have been developed (Mendelson and Mello, 1996; SAMHSA, 2000), but advances in understanding the neurobiological bases of cocaine abuse have led to several pharmacological approaches to treatment. There is considerable evidence that the abuse-related effects of cocaine are mediated by

*Correspondence: Dr NK Mello, Alcohol and Drug Abuse Research Center, McLean Hospital-Harvard Medical School, II5 Mill Street, Belmont, MA 02478, USA, Tel: + I 617855 2716, Fax: + I 617855 2519, E-mail: mello@mclean.harvard.edu

Received 13 April 2004; revised 27 October 2004; accepted 29 October 2004

Online publication: I November 2004 at http://www.acnp.org/citations/ NPPI I $0104040169 /$ default/pdf increases in extracellular levels of dopamine in the terminal fields of the mesolimbic dopamine system (Kuhar et al, 1991; Spealman et al, 1992; Carroll et al, 1999; Platt et al, 2002). Accordingly, compounds that modulate dopaminergic activity have been extensively evaluated in preclinical studies as potential treatments for cocaine abuse and dependence (Mello and Negus, 1996; Carroll et al, 1999; Howell and Wilcox, 2001; Platt et al, 2002). Unfortunately, most of these compounds have not been approved for clinical use by the Food and Drug Administration (FDA).

An alternative approach to the medication-based treatment of cocaine abuse has been to study compounds that can modulate dopaminergic activity indirectly by acting on other receptor systems (Carroll et al, 1999; Bergman et al, 2000; Mello and Negus, 2000). Kappa opioid agonists are one candidate medication for cocaine abuse treatment (Archer et al, 1996; Mello and Negus, 2000). Accumulating evidence from in vivo and in vitro studies shows that pharmacological modulation of kappa opioid receptors can affect the activity of dopaminergic neurons that are 
involved in mediating the neurochemical and behavioral effects of cocaine (Mello and Negus, 2000). For example, high levels of kappa opioid receptors and their endogenous agonist, dynorphin, have been found in the nucleus accumbens (Meng et al, 1993; Mansour et al, 1994; Svingos et $a l, 1999)$. Elevated levels of dynorphin and overexpression of kappa opioid receptors have also been found after chronic cocaine treatment (Spangler et al, 1996; Shippenberg et al, 2001; Yuferov et al, 2001). Administration of kappa agonists has been shown to decrease basal and cocaine-stimulated dopamine levels in microdialysis studies (Di Chiara and Imperato, 1988; Devine et al, 1993; Maisonneuve et al, 1994).

Behavioral studies indicate that kappa opioid agonists also attenuate cocaine-induced increases in locomotor activity as well as the development of sensitization to cocaine's effects on locomotor activity and stereotypy in rats (Crawford et al, 1995; Schenk et al, 2001; Shippenberg et al, 2001). In addition, kappa opioid agonists have been found to decrease cocaine-seeking behavior in rodent models of intravenous (i.v.) self-administration and relapse, as well as place preference (Glick et al, 1995; Kuzmin et al, 1997; Schenk et al, 2001; Shippenberg et al, 2001). Kappa opioid agonists also produced dose-dependent and sustained decreases in cocaine self-administration in rhesus monkeys (Negus et al, 1997; Mello and Negus, 1998b, 2000). Importantly, side effects (eg emesis and sedation) sometimes observed at the beginning of chronic treatment rapidly subsided within 2 or 3 days (Negus et al, 1997; Mello and Negus, 1998b, 2000).

Archer and co-workers first postulated that kappa and $\mathrm{mu}$ opioid combinations might be useful for treatment of cocaine abuse, because both kappa agonists and mu antagonists reduce dopamine release from the nucleus accumbens (Archer et al, 1996). In support of this hypothesis, compounds with mixed activity at kappa and $\mathrm{mu}$ opioid receptors (eg ethylketocyclazocine (EKC), Mr2033) decreased cocaine self-administration by rhesus monkeys more consistently, and with fewer side effects than selective kappa opioid agonists (Negus et al, 1997; Mello and Negus, 1998b, 2000). Both EKC and Mr2033 appear to act as low efficacy agonists at mu opioid receptors and as high efficacy agonists at kappa opioid receptors. Subsequent studies in rhesus monkeys confirmed that mixed mu/kappa opioids were more effective in reducing cocaine selfadministration than kappa selective opioids, and produced minimal side effects (Bowen et al, 2003). Taken together, these studies suggested that mixed mu/kappa opioids may provide a useful approach to treatment of cocaine abuse.

Translation of the preclinical findings into clinical evaluations of kappa and mixed mu/kappa opioid agonists for cocaine abuse treatment has been hindered by the limited number of kappa opioids approved for clinical use (Walsh et al, 2001a, b). In humans, kappa selective agonists can produce fatigue, sedation, confusion, anxiety, and at higher doses, visual and auditory distortions and depersonalization (Pfeiffer et al, 1986; Reece et al, 1994). However, drug use history influences the subjective effects produced by kappa opioids. For example, in men with no history of drug abuse, enadoline, a selective kappa agonist (5-25 $\mu \mathrm{g}$ ), produced a number of adverse effects (Reece et al, 1994), whereas in opioid abusers, enadoline in doses up to $80 \mu \mathrm{g}$ was well tolerated and produced some dysphoria and sedation (Walsh et al, 2001a). Higher doses of enadoline $(160 \mu \mathrm{g})$ had psychomimetic effects including visual and perceptual disturbances, dysphoria, and hallucinations (Walsh et al, 2001a).

Nalbuphine (Nubain ${ }^{\circledR}$ ) is classified as a mixed action mu antagonist/kappa agonist, and is clinically available as an analgesic (Jaffe and Martin, 1990; Preston and Jasinski, 1991; PDR, 2003). Nalbuphine is purported to have relatively low abuse liability and is not scheduled by the FDA (PDR, 2003). We selected nalbuphine for clinical evaluation because of its relatively long duration of analgesic action and safety profile (Zacny et al, 1997; PDR, 2003). Moreover, nalbuphine produced significant and sustained reductions in cocaine self-administration by rhesus monkeys without altering food-maintained responding (Negus and Mello, 2002). Nalbuphine also produced dose-dependent downward shifts in the cocaine selfadministration dose-effect curve (Negus and Mello, 2002).

The present study was conducted under double-blind, placebo-controlled conditions in men who met American Psychiatric Association Diagnostic and Statistical Manual (DSM-IV) criteria for current cocaine abuse. The effects of nalbuphine alone, cocaine alone, and nalbuphine + cocaine in combination on cardiovascular and subjective responses were examined. Each subject was studied as his own control across conditions.

\section{METHODS}

\section{Subjects}

Subjects were recruited via local newspaper advertisements. A total of 12 men provided written informed consent for participation in this study, but five subjects withdrew for personal reasons. The final data are presented for seven men who were studied under all three drug conditions. The study was approved by the Institutional Review Board of the McLean Hospital. Subject confidentiality was protected by a Confidentiality Certificate from the National Institute on Drug Abuse (NIDA) as well as by compliance with HIPAA health privacy regulations. All subjects fulfilled DSM-IV criteria for a diagnosis of current cocaine abuse (305.6). Volunteers with any lifetime DSM-IV Axis I disorder other than cocaine abuse and nicotine dependence (305.1) were excluded. All men selected for the study were in good physical health and medical examinations and laboratory screening profiles were normal. These subjects did not differ significantly with respect to age $(26.14 \pm 1.58$ years), body mass index $(25.07 \pm 1.06)$, education ( $13 \pm 0.69$ years), and reported history of cocaine abuse ( $6 \pm 0.9$ years). All subjects reported using cocaine at least once and up to four times during the last month. Three of the seven subjects were occasional cigarette smokers (five to 10 cigarettes per day) and did not meet DSM-IV criteria for nicotine dependence. All subjects were paid for their participation in the study.

\section{Study Design and Rationale for Drug Dose Selection}

The effects of nalbuphine (Nubain ${ }^{\circledR}$ ) on cocaine-induced changes in cardiovascular measures and subjective re- 
sponses were studied. Each subject served as his own control across the three drug treatment conditions: (1) nalbuphine alone $(5 \mathrm{mg} / 70 \mathrm{~kg}$, i.v. plus placebo-cocaine), (2) cocaine alone $(0.2 \mathrm{mg} / \mathrm{kg}$, i.v. plus placebo-nalbuphine), and (3) nalbuphine $(5 \mathrm{mg} / 70 \mathrm{~kg}$, i.v.) plus cocaine $(0.2 \mathrm{mg} /$ $\mathrm{kg}$, i.v.)). Drugs were administered in an irregular order on three successive study days separated by one or more weeks. Each placebo condition consisted of administration of an equal volume of i.v. saline. Each test session lasted for $150 \mathrm{~min}$.

Cocaine. A dose of $0.2 \mathrm{mg} / \mathrm{kg}$ i.v. cocaine has proven to be safe and to induce significant changes in mood states and physiological responses in our previous clinical studies. This dose of cocaine usually produces peak plasma cocaine levels of approximately $100 \mathrm{ng} / \mathrm{ml}$ (Kaufman et al, 1998; Mendelson et al, 1998, 2001; Sholar et al, 1998).

Nalbuphine. The analgesic potency of nalbuphine is equivalent to that of morphine and the recommended analgesic dose is 10 to $20 \mathrm{mg} / 70 \mathrm{~kg}$ (PDR, 2003). In normal healthy volunteers, $10 \mathrm{mg} / 70 \mathrm{~kg}$ nalbuphine and morphine produce similar subjective and physiological effects (Zacny et al, 1997). However, in the present study, $10 \mathrm{mg} / 70 \mathrm{~kg}$ nalbuphine produced vomiting and sedation in three men, so a lower dose of $5 \mathrm{mg} / 70 \mathrm{~kg}$ was used. Two of these subjects completed the study and one withdrew. Nalbuphine doses of 5 or $6 \mathrm{mg} / 70 \mathrm{~kg}$ produced some positive subjective effects (eg High, Like Drug Effects, Feel Drug Effect) in previous studies (Zacny et al, 1997; Preston and Bigelow, 2000).

\section{Drug Abstinence Requirements}

Subjects were asked to abstain from smoking and drinking alcohol or caffeinated beverages after midnight before the study. Also, subjects were required not to eat food or drink any nonclear liquids for $4 \mathrm{~h}$, and not to drink clear liquids for $2 \mathrm{~h}$ before the study session. It is important for subject safety, as well as to avoid confounding of the dependent variables, to ensure that subjects have not used any drugs before administration of i.v. cocaine or nalbuphine. On the morning of each study day, subjects provided a urine sample for analysis with The Triage ${ }^{\circledR}$ toxicology screen panel for Drugs of Abuse (Biosite Diagnostics, San Diego, CA). Subjects were also given a breath alcohol test (Alco-Sensor IV, Intoximeters, Inc., St Louis, MO). All subjects were drug and alcohol free at the time of the study.

\section{Experimental Conditions}

These studies were carried out on a clinical research ward used exclusively for studies of substance abuse. Only one subject was studied on each experimental day. Subjects sat in a comfortable chair in front of a computer that was used to collect subjective responses throughout the test session. Subjective responses and physiological data were collected at $15 \mathrm{~min}$ prior to nalbuphine administration and for $2 \mathrm{~h}$ and $15 \mathrm{~min}$ after nalbuphine administration. Subjective measures included a Visual Analog Scale (VAS), a SubjectRated Adjective Checklist, and the short form of the
Addiction Research Center Inventory (ARCI) (Martin et al, 1971).

After completion of the baseline subjective effects questionnaires, a physician administered nalbuphine or placebo i.v. over $15 \mathrm{~s}$ into the subject's antecubital vein. After $15 \mathrm{~min}$, cocaine or placebo was administered i.v. over $1 \mathrm{~min}$ in a volume of $1 \mathrm{ml}$. Heart rate, pulse oxymetry, and systolic and diastolic blood pressure were monitored throughout the study session with a noninvasive patient monitor model (Scholar II/507E, Criticare Systems, Waukesha, WI). Subjects and research assistants did not know if active drug or placebo was administered. For safety reasons, the hospital pharmacy informed the physician of what each syringe contained. Vital signs were monitored for at least $4 \mathrm{~h}$ after completion of the study. A physician certified in cardiopulmonary resuscitation was present during each study, and a cardiac defibrillator and appropriate emergency treatment medications were located in the study room.

\section{Sample Collection Procedures}

All samples for cocaine and nalbuphine analysis were collected from an i.v. catheter placed in the antecubital vein of the arm opposite the arm used for cocaine or nalbuphine injection. Baseline blood samples for analysis of plasma drug levels were collected at $15 \mathrm{~min}$ before nalbuphine injection and $30 \mathrm{~min}$ before i.v. cocaine injection. Samples for analysis of serum nalbuphine levels were collected 10, $20,25,45$, and $135 \mathrm{~min}$ after nalbuphine injection. Samples for plasma cocaine analyses were collected at $2,4,8,12,16$, $20,25,30,45,60,90$, and $120 \mathrm{~min}$ after cocaine injection. This rapid sampling frequency was based on previous observations that cocaine levels in venous blood increase rapidly within 2 min after i.v. administration and reach peak levels within 4 to $5 \mathrm{~min}$ (Evans et al, 1996; Sholar et al, 1998; Mendelson et al, 1999, 2001, 2002).

\section{Subjective Effect Measures}

Subjective effect measures included computerized versions of a VAS, a short form of the ARCI (Martin et al, 1971), and a Subject-Rated Adjective Checklist. Items included on the VAS and the Adjective Checklist were based on previous clinical studies of opioid effects and cocaine effects (Preston et al, 1989; Foltin and Fischman, 1992; Zacny et al, 1997; Walsh et al, 2001a). Subjective effect ratings were completed at baseline and periodically after nalbuphine and cocaine administration.

Visual Analog Scales. On the 13-item VAS scale, subjects were asked to rate the following drug effects: High, Stimulated, Drug Effect, Good Effect, Euphoria, Sick, Dizzy, Alert, Itchy, Anxious, Bad Effect, Craving, and Sleepy. Each of the 13 items was rated from 0 (not at all) to 100 (extremely) on a $100 \mathrm{~mm}$ line on the computer screen. VAS ratings were completed at $10,20,25,30,35,40$, $45,60,75,105$, and $135 \mathrm{~min}$ after nalbuphine or placebonalbuphine administration, or at $5,10,15,20,25,30,45$, 60 , 90, and $120 \mathrm{~min}$ after cocaine or placebo-cocaine administration. The VAS scale was usually completed within 1-2 min. 
Addiction Research Center Inventory. The ARCI consists of 49 true/false questions, and four subscales were analyzed: (1) the morphine-benzedrine scale (MBG), an index of euphoria; (2) the LSD scale, an index of dysphoria; (3) the PCAG scale, an index of sedation; and (4) the amphetamine, benzedrine scales (AMP), an index of amphetamine-like effects. The ARCI was administered at baseline and at $45 \mathrm{~min}$, and $135 \mathrm{~min}$ after nalbuphine or placebo-nalbuphine injection, and this corresponds to 30 and $120 \mathrm{~min}$ after cocaine or placebo-cocaine injection. As in previous studies, the ARCI was usually completed within $5 \mathrm{~min}$ (Foltin and Fischman, 1991).

Subject-Rated Adjective Checklist. A Subject-Rated Adjective Checklist consisted of the following 15 items: Excited, Energetic, Fearful, Suspicious, Nervous, Sweaty, Drunk, Itchy, Tingling, Lightheaded, Spaced-Out, Confused, Irritable, Jittery, and Nauseous. Each item was rated on a fivepoint scale from 1 (indicating 'not at all') to 5 (indicating 'extremely'). Subjects were asked to rate these adjectives at baseline, and at 10, 20, 25, 30, 35, 40, 45, 60, 75, 105, and $135 \mathrm{~min}$ after nalbuphine injection, and this corresponds to $5,10,15,20,25,30,45,60,90$, and $120 \mathrm{~min}$ following cocaine/saline injection. This questionnaire was usually completed within 1-2 min.

\section{Physiological Measures}

Heart rate, systolic and diastolic blood pressure, and arterial oxygen saturation were monitored throughout the session. Oxygen saturation and heart rate data were collected continuously using an automatic physiologic device (Noninvasive Patient Monitor model Scholar II/507E, Criticare Systems, Waukesha, WI). Systolic and diastolic blood pressure was measured periodically at baseline, and 10, $20,25,30,35,40,45,60,75,105$, and $135 \mathrm{~min}$ after nalbuphine or placebo-nalbuphine injection, and this corresponds to $5,10,15,20,25,30,45,60,90$, and 120 min after cocaine or placebo-cocaine injection.

\section{Nalbuphine and Cocaine Preparation}

Nalbuphine hydrochloride was obtained from a commercial source (Endo Pharmaceuticals Inc., Chadds Ford, PA). The nalbuphine dose was prepared from a preformulated stock solution (Nubain ${ }^{\circledR} 20 \mathrm{mg} / \mathrm{ml}$ ) by diluting it to the correct volume with $0.9 \%$ sterile saline. The nalbuphine dose was based on body weight and is expressed as milligrams of the salt weight per $70 \mathrm{~kg}$ body weight. Placebo nalbuphine consisted of the same volume of sterile saline $(0.9 \%)$ for injection.

Cocaine hydrochloride was acquired from the NIDA in powder form and was dissolved in sterile water for i.v. injection by the McLean Hospital pharmacy. Sterility was ensured by passing the solution through a $0.22 \mu \mathrm{m}$ Millipore filter and subjecting it to Limulus Amebocyte Lysate (LAL) test for detection of Gram-negative bacterial endotoxins. The test kit is manufactured by Whittaker Bioproducts, Walkersville, MD. Placebo cocaine consisted of the same volume of sterile saline for injection.

\section{Nalbuphine and Cocaine Analysis}

Serum concentrations of nalbuphine were measured in duplicate using a solid-phase ELISA purchased from Neogen Corporation (Lexington, KY), with SIGMA (St Louis, MO) standard N-4396. The assay sensitivity was $0.06 \mathrm{ng} / \mathrm{ml}$ and the intra- and interassay CVs were 5.4 and 6.5\%, respectively.

Plasma cocaine levels were measured in duplicate using a solid-phase extraction method described by SPEC Instruction Manual by Ansys with a Hewlett-Packard 5890 Series II gas chromatograph equipped with a capillary column and a Hewlett-Packard 5971 Series Mass selective detector (Abusada et al, 1993). The assay sensitivity is $10 \mathrm{ng} / \mathrm{ml}$ and the intra- and interassay CVs were 4.1 and $3.4 \%$, respectively.

\section{Data Analysis}

To determine if changes in the dependent measures from baseline were statistically significant, all cardiovascular and subjective effects measures were analyzed by within-subject single factor analysis of variance (ANOVA). To evaluate the interaction between nalbuphine and cocaine, time-course data for heart rate, systolic and diastolic blood pressure, and all subjective effect measures were analyzed by two-way ANOVA for repeated measures (drug condition $\times$ time). All ANOVAs were based on the first $30 \mathrm{~min}$ after cocaine or placebo-cocaine administration. Significant main effects and interaction effects were further evaluated by use of post hoc comparisons of all three drug conditions to each other at each time point. Results were considered significant when $p<0.05$. A Huynh-Feldt correction for sphericity was used for all repeated measures data.

Area under the curve (AUC) was analyzed for VAS ratings and Subject-Rated Adjective Checklist ratings using GraphPad Prism (Version 4.0) (GraphPad Software, San Diego, CA). This analysis has the advantage of quantifying both peak levels and duration of the subjective effect changes. An AUC was calculated for each subject for each subjective effects item under each of the three drug conditions. The AUCs for the group average for nalbuphine alone, cocaine alone, and nalbuphine + cocaine were compared with ANOVA for repeated measures. Newman-Keuls post-tests were used to compare each drug condition.

The peak levels of cocaine in plasma usually occurred within 4 to $5 \mathrm{~min}$ after i.v. administration. The VAS and Subject-Rated Adjective Checklist ratings at $5 \mathrm{~min}$ post cocaine each were compared with paired $t$-tests for nalbuphine alone, cocaine alone, and nalbuphine + cocaine in combination.

Estimates of the primary kinetic parameters (ie time to peak plasma concentrations $\left(T_{\mathrm{MAX}}\right)$, peak plasma concentration $\left(C_{\mathrm{MAX}}\right)$, and half-life $\left.\left(t_{1 / 2}\right)\right)$ of plasma cocaine were obtained directly from a nonlinear regression-estimation software program based on the Manual of Pharmacologic Calculations with Computer programs using PHARM/PCS Version 4.2 (MicroComputer Specialist MCS, Philadelphia, PA).

\section{RESULTS}

\section{Nalbuphine and Cocaine Levels (Figure 1)}

Nalbuphine. Drug levels in blood after administration of $5 \mathrm{mg} / 70 \mathrm{~kg}$ i.v. nalbuphine and $0.2 \mathrm{mg} / \mathrm{kg}$ i.v. cocaine are 

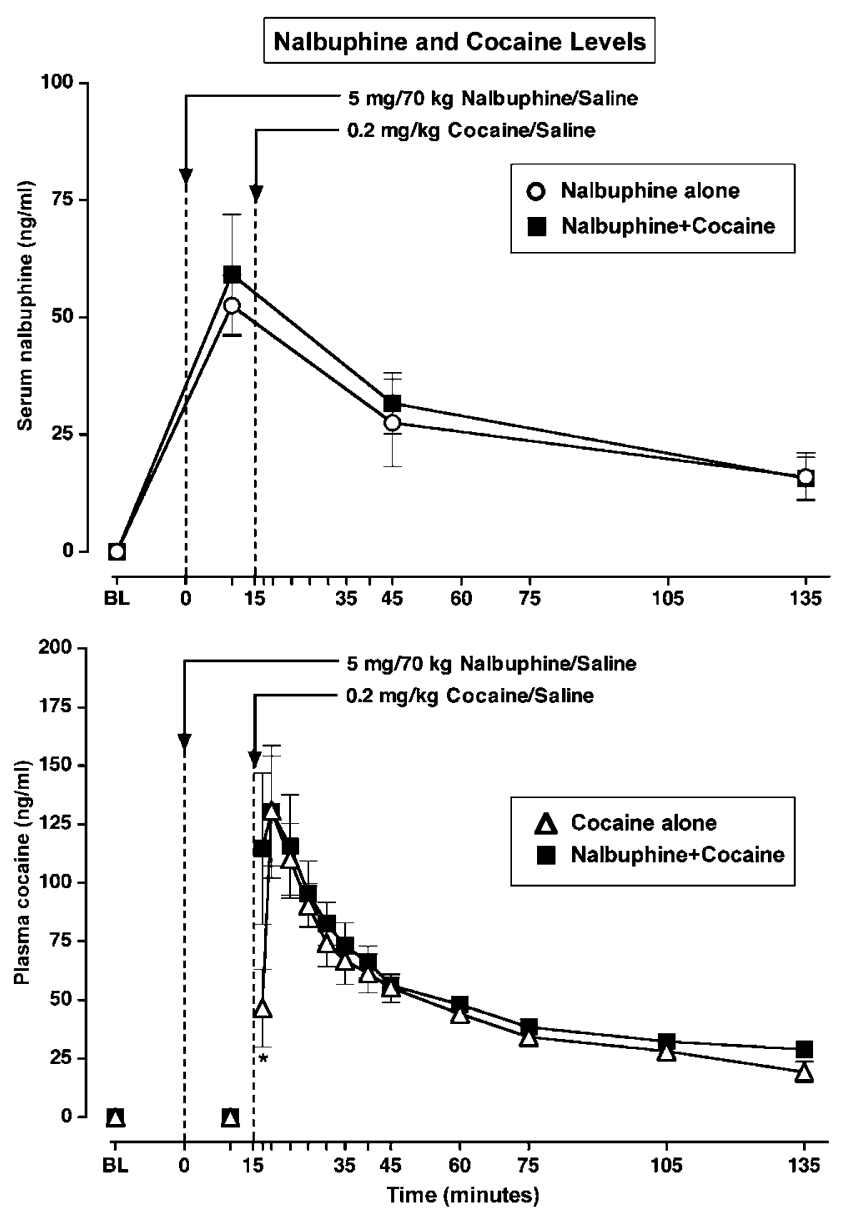

Figure I Blood levels of nalbuphine and cocaine. In each panel, baseline (BL) and time ( $\mathrm{min}$ ) after nalbuphine administration (0-135 min) are shown on the abscissa and serum or plasma drug levels are shown on the left ordinate. The dotted line above zero indicates when nalbuphine was administered and the dotted line above 15 min indicates when cocaine was administered. Top panel: Levels of nalbuphine $(\mathrm{ng} / \mathrm{ml})$ after nalbuphine alone (open circles) and nalbuphine + cocaine (closed squares). Each data point is the average $(\bar{x} \pm$ SEM) of seven subjects. Lower panel: Plasma cocaine levels $(\mathrm{ng} / \mathrm{ml})$ after cocaine alone (open triangles) and nalbuphine + cocaine (closed squares). Each data point is the average $(\bar{x} \pm$ SEM) of seven subjects. A significant difference between plasma cocaine at 2 min after cocaine alone and nalbuphine + cocaine is indicated by an asterisk $(p<0.005)$.

shown in Figure 1. When nalbuphine alone was administered, serum levels at $10 \mathrm{~min}$ after i.v. nalbuphine administration averaged $52.5 \pm 6.5 \mathrm{ng} / \mathrm{ml}$ and gradually decreased to average $16 \pm 5.1 \mathrm{ng} / \mathrm{ml}$ at $135 \mathrm{~min}$ after nalbuphine (Figure 1, top panel). When nalbuphine was given in combination with cocaine, peak serum nalbuphine levels averaged $59.2 \pm 12.8 \mathrm{ng} / \mathrm{ml}$ within $10 \mathrm{~min}$ after nalbuphine ( 5 min before cocaine administration) and gradually decreased to average $15.7 \pm 4.5 \mathrm{ng} / \mathrm{ml}$ at $135 \mathrm{~min}$ after nalbuphine. There were no statistically significant differences in serum nalbuphine levels when nalbuphine was given alone in comparison to nalbuphine given in combination with cocaine. No nalbuphine was detected in serum after placebo-nalbuphine injection.

Cocaine. When cocaine alone was administered, peak cocaine plasma levels of $131 \pm 29.46 \mathrm{ng} / \mathrm{ml}$ were measured at $4 \mathrm{~min}$ (Figure 1, lower panel). Plasma cocaine levels gradually decreased to average $19 \pm 4.4 \mathrm{ng} / \mathrm{ml}$ at $135 \mathrm{~min}$. The calculated half-life $\left(t_{1 / 2}\right)$ of cocaine in plasma was $49.4 \pm 7.7 \mathrm{~min}$. Importantly, pretreatment with nalbuphine did not affect cocaine pharmacokinetics. When cocaine was administered $15 \mathrm{~min}$ after nalbuphine peak, plasma cocaine levels of $130 \pm 28.2 \mathrm{ng} / \mathrm{ml}$ were measured within $4 \mathrm{~min}$ after cocaine injection. However, at $2 \mathrm{~min}$ after cocaine administration, plasma cocaine levels were significantly higher after nalbuphine administration than after cocaine alone $(p<0.005)$. Plasma cocaine levels gradually decreased to average $29 \pm 1.72 \mathrm{ng} / \mathrm{ml}$ at $120 \mathrm{~min}$ after cocaine. The calculated half-life $\left(t_{1 / 2}\right)$ of cocaine in plasma was $51.5 \pm 6.1 \mathrm{~min}$. No cocaine was detected in plasma after placebo-cocaine injection.

\section{Cardiovascular Effects of Nalbuphine, Cocaine, and Nalbuphine + Cocaine Combinations (Figure 2)}

Cardiovascular effects of nalbuphine alone. Baseline values for heart rate and systolic and diastolic blood pressure averaged $69.4 \pm 1.7$ beats $/ \mathrm{min}$ and $121.3 \pm 2.8$ and $74.4 \pm 1.2 \mathrm{mmHg}$, respectively. Nalbuphine had no significant effect on heart rate and systolic blood pressure. Nalbuphine decreased diastolic blood pressure within $35 \mathrm{~min}$ and these decreases were statistically significant at $75 \mathrm{~min}(p=0.04)$ and $105 \mathrm{~min}(p=0.04)$ after nalbuphine administration and returned to baseline at the end of study session. Oxygen saturation did not change significantly after nalbuphine administration (data not shown).

Cardiovascular effects of cocaine alone. Baseline values for heart rate and systolic and diastolic blood pressure averaged $73.4 \pm 3.9$ beats $/ \mathrm{min}$ and $119 \pm 4.0$ and $75.1 \pm 2.3 \mathrm{mmHg}$, respectively. Cocaine increased heart rate significantly, and this increase was sustained for 25 min. Peak increases in heart rate were observed at $10 \mathrm{~min}$ after cocaine injection and averaged $101 \pm 24$ beats $/ \mathrm{min}(p=0.002)$. Systolic blood pressure increased significantly above baseline within $5 \mathrm{~min}$ after cocaine injection $(p=0.02)$ and peak levels of $142 \pm 9 \mathrm{mmHg}$ were measured at $10 \mathrm{~min}$ after cocaine injection $(p=0.001)$. Systolic blood pressure remained significantly elevated for the first $15 \mathrm{~min}$ after cocaine injection $(p=0.005)$ and then returned to baseline levels. Diastolic blood pressure tended to increase after cocaine, but those changes were not statistically significant. Oxygen saturation did not change significantly after cocaine administration (data not shown).

Cardiovascular effects of nalbuphine + cocaine in combination. Baseline values for heart rate and systolic and diastolic blood pressure averaged $68.6 \pm 1.5$ beats $/ \mathrm{min}$ and $119.4 \pm 2.8$ and $78.6 \pm 2.8 \mathrm{mmHg}$, respectively. Heart rate increased significantly above the baseline within $5-30 \mathrm{~min}$ following cocaine injection when nalbuphine $(5 \mathrm{mg} / 70 \mathrm{~kg})$ and cocaine $(0.2 \mathrm{mg} / \mathrm{kg})$ were given in combination. Peak increases in heart rate of $97 \pm 20$ beats/min were observed at $5 \mathrm{~min}(p=0.0003)$ after cocaine injection, and the magnitude of this increase in heart rate was similar to that after cocaine alone. Systolic blood pressure also increased significantly above baseline following administration of 


\section{Cardiovascular Effects of Nalbuphine $(0, O)$, Cocaine $(\Delta, \Delta)$ and Nalbuphine + Cocaine $(\square, \square)$}
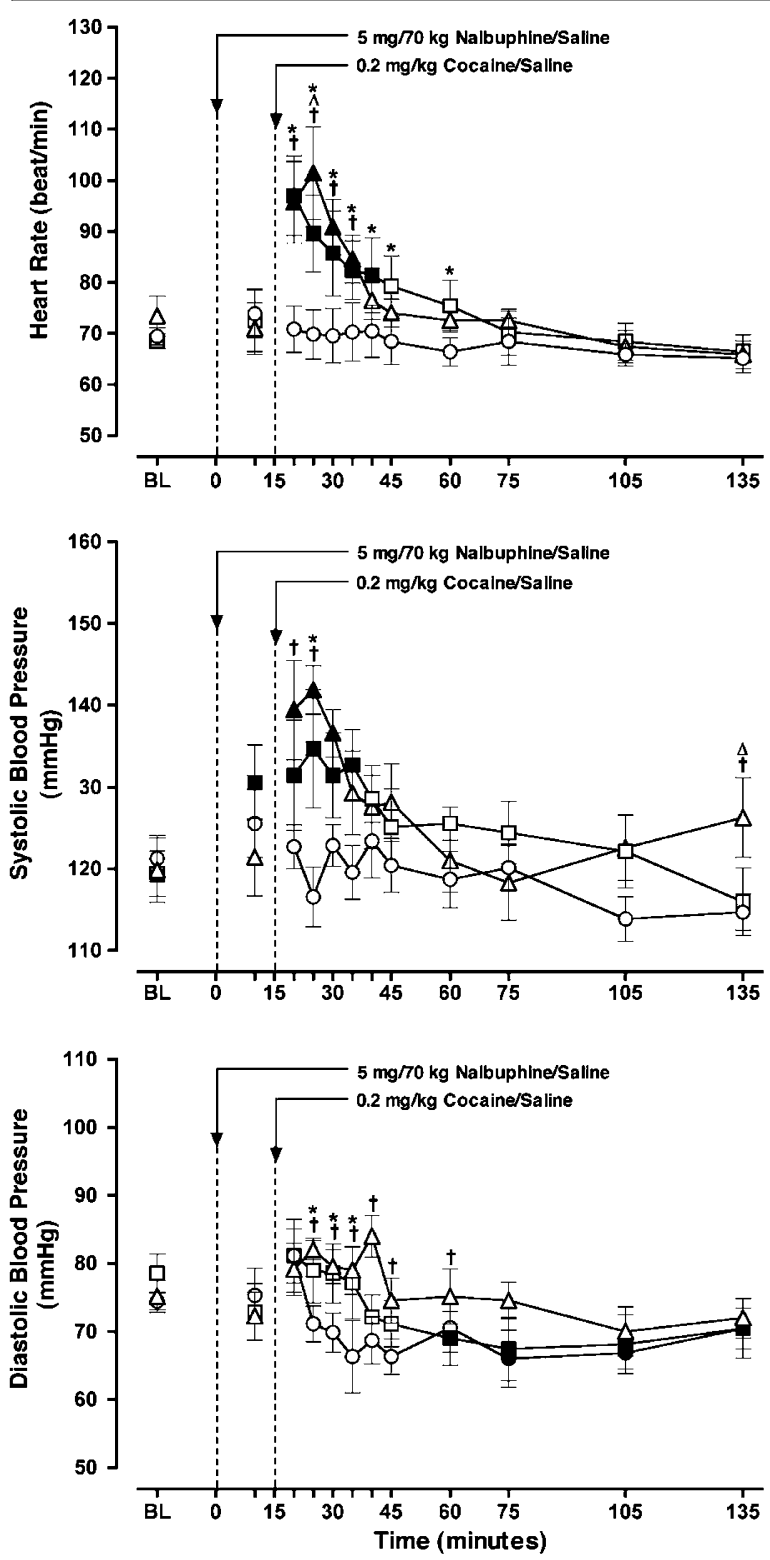

Figure 2 Cardiovascular effects of nalbuphine, cocaine, and nalbuphine + cocaine: Baseline (BL) and successive time points (min) after nalbuphine administration at time zero are shown on the abscissa of each panel. The dotted line above zero indicates the time of nalbuphine or saline placebo administration. The dotted line above 15 min indicates the time of cocaine or saline placebo administration. Top panel: Heart rate in beats/min is shown on the left ordinate. Middle panel: Systolic blood pressure $(\mathrm{mmHg})$ is shown on the left ordinate. Lower panel: Diastolic blood pressure $(\mathrm{mmHg})$ is shown on the left ordinate. In each panel, nalbuphine is indicated by circles, cocaine is indicated by triangles, and nalbuphine + cocaine in combination is indicated by squares. The filled symbols indicate points that were significantly different from baseline $(B L)(p<0.05)$. The open symbols indicate points that were not significantly different from baseline. Significant differences between nalbuphine and nalbuphine + cocaine in combination are indicated by asterisks $(p<0.05)$. Significant differences between cocaine and nalbuphine + cocaine in combination are indicated by small triangles $(\Delta)(p<0.05)$. Significant differences between nalbuphine and cocaine are indicated by dagger $(\dagger)$ symbols $(p<0.05)$. Each data point is the average ( $\bar{x} \pm$ SEM) of seven subjects. nalbuphine and cocaine. A peak increase in systolic blood pressure of $141.9 \pm 3.0 \mathrm{mmHg}$ was measured at $10 \mathrm{~min}$ $(p=0.02)$ after cocaine injection and remained significantly elevated for $15 \mathrm{~min}$ following cocaine injection. Nalbuphine and cocaine in combination produced significant decreases in diastolic blood pressure as compared to baseline within 45 min after cocaine injection $(p=0.02)$. Oxygen saturation did not change significantly after nalbuphine + cocaine administration (data not shown).

\section{Subjective Effects of Nalbuphine, Cocaine, and Nalbuphine + Cocaine Combinations (Figure 3, Tables 1 and 2)}

\section{Subjective effects of nalbuphine alone.}

Visual Analog Scale: The time course of changes in VAS ratings after nalbuphine administration is shown in Figure 3 and overall changes are shown in Table 1. Nalbuphine produced significant increases in VAS ratings of High and Stimulated (Figure 3), Good Effect, Euphoria, Drug Effect, Sleepy, Dizzy, and Bad Effect (Table 1) in comparison to baseline ratings $(p<0.0001-0.03)$. VAS ratings of High, Stimulated, Good Effect, Drug Effect, and Euphoria increased significantly within $10-25 \mathrm{~min}$ after nalbuphine administration and remained significantly above baseline ratings for $45-135 \mathrm{~min}(p<0.05)$ (Figure 3). Nalbuphine significantly decreased VAS ratings of Alert within $20 \mathrm{~min}$, and the greatest decreases were observed at $60 \mathrm{~min}$ after nalbuphine administration $(p<0.0001)$. Nalbuphine significantly increased VAS ratings of Sleepy, and increases were maximal at $60 \mathrm{~min}$ after nalbuphine administration $(p<0.02)$. Nalbuphine did not have significant effects on VAS ratings of Sick, Itchy, Anxious, or Craving (Table 1).

Subject-Rated Adjective Checklist: Nalbuphine significantly increased ratings of Drunk, Tingling, Lightheaded, and Spaced-Out, and decreased ratings of Excited, Energetic, Suspicious, and Nervous in comparison to baseline ratings $(p<0.05)$. Ratings of Fearful, Sweaty, Itchy, Confused, Irritable, Jittery, and Nauseous did not change significantly in comparison to baseline ratings (Table 1).

Addiction Research Center Inventory: Ratings on all four ARCI scales (PCAG, MBG, LSD, and amphetamine) increased significantly from baseline when measured at $45 \mathrm{~min}$ after nalbuphine injection $(p<0.0001-0.01)$ (Table 2 , column 1).

\section{Subjective effects of cocaine alone.}

Visual Analog Scale: VAS ratings after cocaine alone are shown in Figure 3 and Table 1. In comparison to baseline ratings, cocaine produced significant increases in ratings of High and Stimulated (Figure 3), Euphoria, Good Effect, Drug Effect, Dizzy, and Craving for cocaine in comparison to baseline ratings $(p<0.0001-0.04)$ (Table 1$)$. Ratings of High, Stimulated, Drug Effect, Good Effect, and Euphoria were maximal within the first 5-10 min after cocaine injection, and then gradually declined. There were no significant effects of cocaine on Alert, Sleepy, Sick, Bad Effect, Itchy, and Anxious. 
Subjective effects of nalbuphine $(O, O)$, cocaine $(\Delta, \Delta)$ and nalbuphine + cocaine $(\square, \square)$

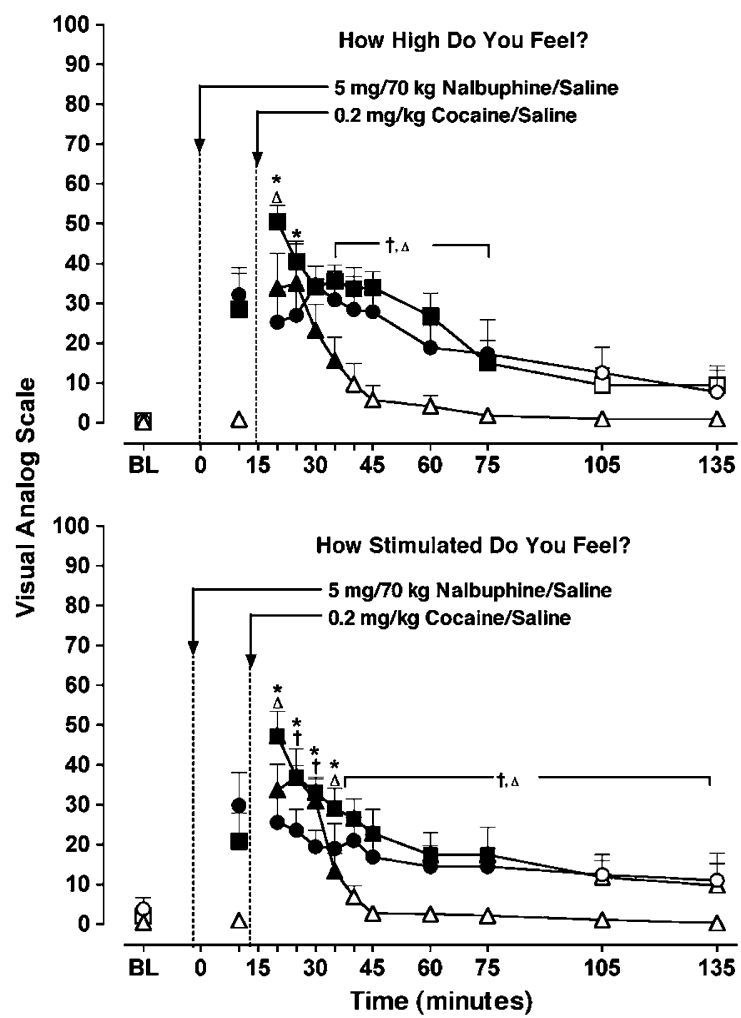

Figure 3 Time course of nalbuphine, cocaine, and nalbuphine + cocaine effects on VAS ratings of high and stimulated. VAS ratings are shown on the left ordinates and the VAS question is shown at the top of each panel. Baseline (BL) and successive time points after nalbuphine administration at time zero are shown on the abscissa of each panel. The dotted line above zero indicates the time of nalbuphine or saline placebo administration. The dotted line above 15 min indicates the time of cocaine or saline placebo administration. Nalbuphine is indicated by circles, cocaine is indicated by triangles, and nalbuphine + cocaine in combination is indicated by squares. The filled symbols indicate points that were significantly different from baseline $(\mathrm{BL})(p<0.05)$. The open symbols indicate points that were not significantly different from baseline. Significant differences between nalbuphine and nalbuphine + cocaine in combination are indicated by asterisks $(p<0.05)$. Significant differences between cocaine and nalbuphine + cocaine in combination are indicated by small triangles $(\Delta)(p<0.05)$. Significant differences between nalbuphine and cocaine are indicated by dagger $(\dagger)$ symbols $(p<0.05)$. Each data point is the average $(\bar{x} \pm$ SEM $)$ of seven subjects.

Subject-Rated Adjective Checklist: Cocaine significantly increased ratings of Energetic, Sweaty, Drunk, Tingling, Lightheaded, Spaced-Out, and Jittery, and decreased ratings of Nervous in comparison to baseline ratings $(p<0.05)$. Ratings of Excited, Itchy, Confused, and Nauseous increased and ratings of Fearful, Suspicious, and Irritable decreased, but these changes were not significantly different from baseline (Table 1).

Addiction Research Center Inventory: Ratings on three ARCI scales (PCAG, LSD, and amphetamine) increased significantly at $30 \mathrm{~min}$ after cocaine administration (45 min after nalbuphine administration) $(p=0.0003-0.05)$. No significant changes were measured at $120 \mathrm{~min}$ after cocaine injection. Cocaine increased MBG scale ratings, but this was not statistically significant (Table 2, column 2).

Subjective effects of nalbuphine + cocaine in combination. Visual Analog Scale: In comparison to baseline ratings, nalbuphine + cocaine in combination produced significant increases in VAS ratings of High and Stimulated (Figure 3), Euphoria, Good Effect, Drug Effect, Dizzy, Sick, Bad Effect, and Craving for Cocaine (Table 1) $(p<0.0001-0.04)$. VAS ratings of High, Stimulated, Good Effect, Drug Effect, and Euphoria were maximal at $5 \mathrm{~min}$ after cocaine administration and remained elevated for the next 45-120 min. In contrast, ratings of Alert decreased significantly after administration of nalbuphine + cocaine in combination $(p<0.01)$ and increases in ratings of Sleepy, Itchy, and Anxious were not significantly different from baseline (Table 1).

Addiction Research Center Inventory: Ratings on all four ARCI scales (PCAG, MBG, LSD, and amphetamine) increased significantly from baseline after nalbuphine + cocaine administration $(p<0.001-0.02)$ (Table 2 , column 3$)$.

Subject-Rated Adjective Checklist: Nalbuphine + cocaine in combination significantly increased ratings of Excited, Sweaty, Drunk, Tingling, Lightheaded, Spaced-Out, and Jittery $(p<0.05)$ in comparison to baseline ratings. There was a trend for nalbuphine + cocaine to increase ratings of energetic $(p=0.09)$ and to decrease ratings of nervous $(p=0.07)$. Ratings of Fearful decreased and ratings of Suspicious, Itchy, Confused, Irritable, and Nauseous increased after nalbuphine + cocaine administration, but these changes were not statistically significant (Table 1).

\section{Comparisons of the Subjective Effects of Nalbuphine Alone, Cocaine Alone, and Nalbuphine + Cocaine (Figures 4, Table 1)}

Visual Analog Scales. Figure 4 shows the average AUC for ratings on VAS items that are usually sensitive to stimulant effects (left column) and/or to opioid effects (right column). Figure 4 also shows average VAS ratings measured at $5 \mathrm{~min}$ after cocaine administration when peak plasma cocaine levels were detected (ie 20 min after nalbuphine). On most measures, the effects of nalbuphine and nalbuphine + cocaine were equivalent. The subjective effects of cocaine alone usually were significantly less that those of nalbuphine + cocaine or nalbuphine alone.

Area under the curve: ANOVA for repeated measures showed a significant main effect for the following stimulantrelated items: Euphoria $(p=0.004)$, High $(p=0.01)$, Stimulated $(p=0.007)$, Good Effect $(p=0.01)$; and opioid-related items: Sleepy $(p=0.03)$, Dizzy $(p=0.009)$. The AUC values for ratings of Euphoria, Good Effect (Figure 4), High, and Stimulated were all significantly lower after cocaine alone than after either nalbuphine alone or nalbuphine + cocaine $(p<0.05-0.01)$. However, ratings of Euphoria, High, Stimulated, Good Effect, and Alert did not differ significantly after administration of nalbuphine alone and nalbuphine + cocaine. Average AUC values for VAS ratings of Sleepy and Dizzy were significantly higher after both nalbuphine 
Table I Subjective Effects of Nalbuphine, Cocaine, and Nalbuphine+Cocaine VAS and Subject-Rated Adjective Checklist

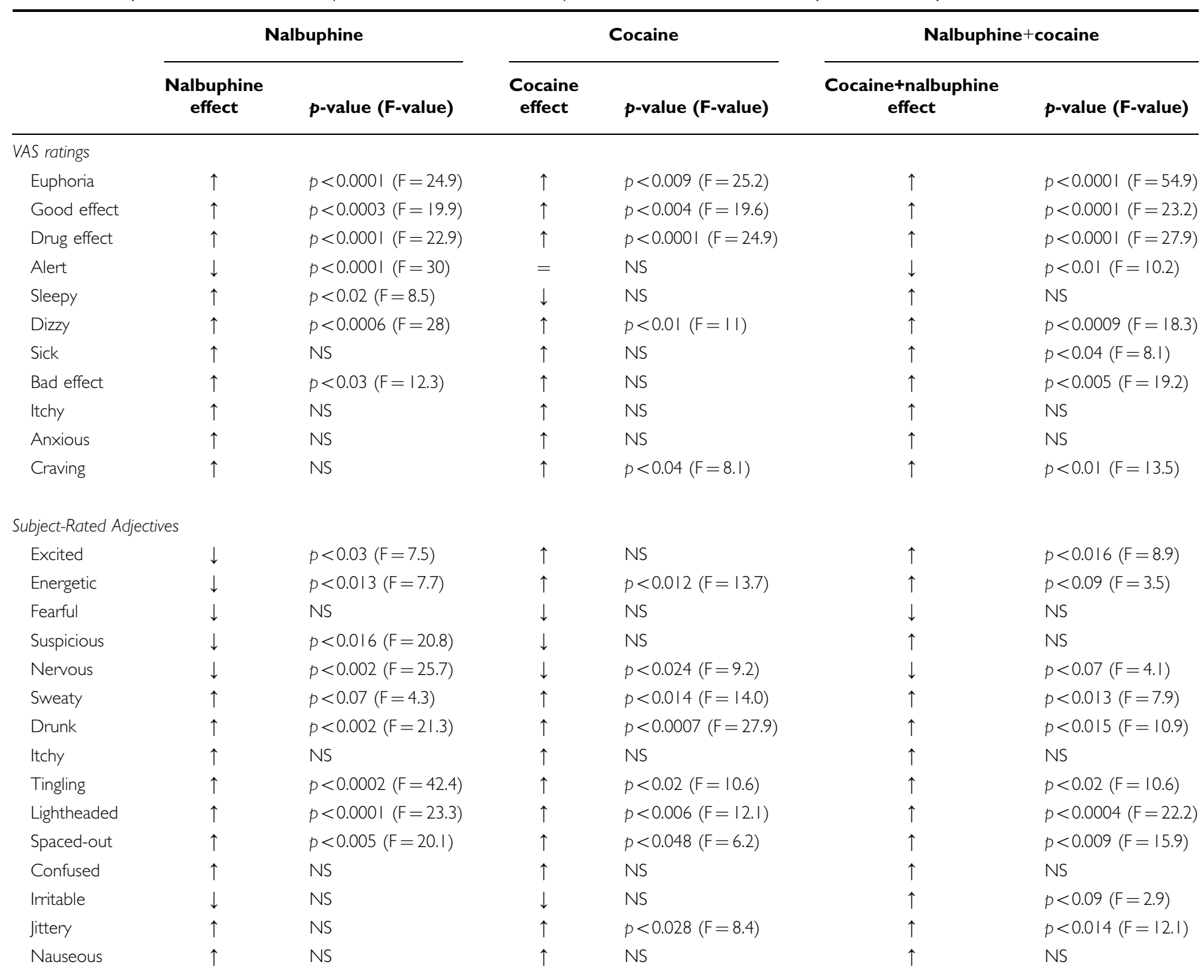

Ratings on VAS and Adjective Checklist items after i.v. nalbuphine alone, cocaine alone, and nalbuphine+cocaine in combination. Arrows denote direction of changes from baseline as an increase $(\uparrow)$ or decrease $(\downarrow)$ for each drug condition, and NS indicates no significant change. $p$-values are shown for significant changes from baseline.

alone and nalbuphine + cocaine than after cocaine alone $(p<0.05-0.01)$ (Figure 4). The VAS ratings of Sleepy, Dizzy, Sick, and Bad Effect did not differ significantly after nalbuphine alone and nalbuphine + cocaine. The average AUC values for VAS ratings of Sick, Bad Effect, Itchy, and Alert did not differ significantly across the three drug conditions.

Peak VAS ratings: Subjects reported significantly greater feelings of Euphoria, High, Stimulated, Alert, and Anxious after administration of nalbuphine + cocaine than after nalbuphine alone $(p<0.05-0.01)$. Ratings of High, Stimulated, and Good Effect were higher after administration of nalbuphine + cocaine than after cocaine alone $(p<0.05)$ (Figure 4, column 1). There were no significant differences between nalbuphine + cocaine and cocaine alone for peak ratings of Sleepy, Dizzy (Figure 4), Sick, Bad Effect, Alert, Itchy, Anxious, or Craving for cocaine (data not shown).
Subject-Rated Adjective Checklist. Figure 4 shows the average AUC for ratings on Subject-Rated Adjective Checklist items that are usually sensitive to stimulant and/or to opioid effects. The stimulant-related items (Excited, Energetic) are shown in the left column and the opioid-related items (Drunk, Spaced-Out) are shown in the right column. Figure 4 also shows peak Adjective Checklist ratings on the same items measured at $5 \mathrm{~min}$ after cocaine administration (ie $20 \mathrm{~min}$ post nalbuphine).

Area under the curve: ANOVA for repeated measures showed a significant main effect for the following items: Energetic $(p=0.026)$, Drunk $(p=0.006)$, Spaced-Out $(p=0.0003)$, and Lightheaded $(p=0.003)$. Ratings of Excited, Energetic, and Jittery were higher after nalbuphine + cocaine than after either cocaine or nalbuphine alone, but these differences were statistically significant only for Energetic $(p<0.05)$. In comparison to cocaine alone, 


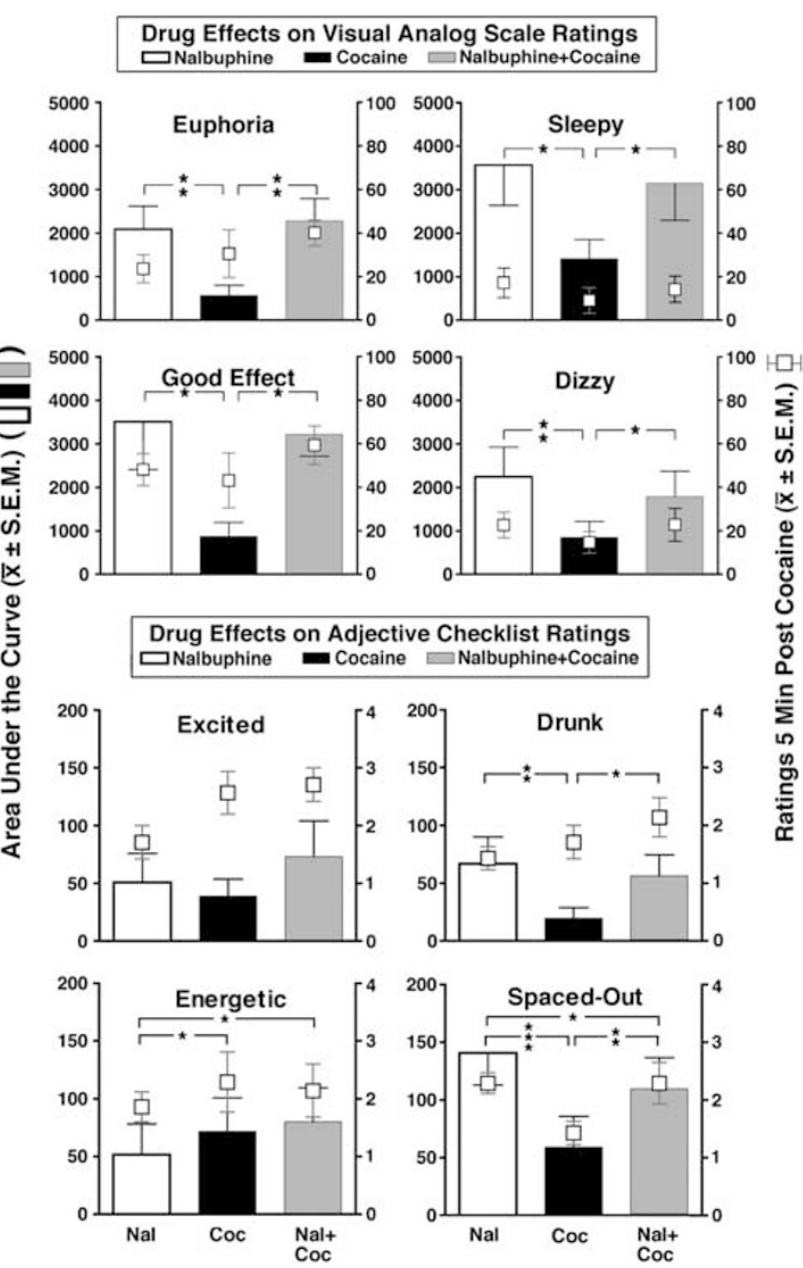

Figure 4 VAS ratings and Subject-Rated Adjective Checklist responses after nalbuphine, cocaine, and nalbuphine + cocaine: comparison of AUC and ratings at 5 min post cocaine. VAS items are shown in rows $I$ and 2 and Adjective Checklist Ratings are shown in rows 3 and 4 . AUC values for subjective effects ratings are shown on the left ordinate, and peak subjective effects ratings at 5 min post cocaine ( 20 min post nalbuphine) are shown on the right ordinate. The three drug conditions are shown on the abscissae. AUC values for VAS and Adjective Checklist ratings after administration of nalbuphine alone (open rectangles), cocaine alone (black rectangles), and nalbuphine + cocaine (gray rectangles) are shown for each item. Significant differences in AUC values for subjective effects ratings between cocaine alone and either nalbuphine alone or nalbuphine + cocaine are indicated by asterisks ( $p<0.05$; $* * 0<0.0$ I). Peak VAS ratings $(\bar{x} \pm$ SEM) measured at 5 min after cocaine administration (ie 20 min post nalbuphine) are shown as open squares superimposed on the AUC rectangles. Significant differences in VAS and Adjective Checklist ratings measured 5 min post cocaine are described in text. Each data point is the average $(\bar{x} \pm$ SEM) of seven subjects.

ratings of Drunk, Spaced-Out, and Lightheaded were significantly higher after both nalbuphine alone and nalbuphine + cocaine $(p<0.05-0.001)$. Ratings of SpacedOut were significantly higher after nalbuphine alone than in combination with cocaine $(p<0.05)$.

Peak Adjective Checklist ratings: There were no significant differences between the three drug conditions in peak Adjective Checklist ratings of Energetic (Figure 4), Lightheaded, Fearful, Suspicious, Nervous, Sweaty, Itchy, Irritable, Tingling, Nauseous, and Confused (data not 
shown). In comparison to nalbuphine alone, peak ratings of Excited, Energetic, Jittery, and Drunk tended to be higher after both cocaine alone and after nalbuphine + cocaine. However, peak ratings were significantly higher after cocaine alone than after nalbuphine alone only for Excited $(p=0.003)$ and Jittery $(p<0.05)$. Ratings after nalbuphine + cocaine were significantly higher than after nalbuphine alone for Excited $(p=0.003)$, Jittery $(p=0.01)$, and Drunk $(p=0.01)$. Ratings of Spaced-Out were significantly higher after either nalbuphine alone $(p=0.02)$ or in combination with cocaine $(p=0.02)$ than after cocaine alone.

Addiction Research Center Inventory. Scores on each of the ARCI subscales were significantly higher after administration of nalbuphine alone than after cocaine alone (Table 2, column 4). Although nalbuphine alone and the combination of nalbuphine + cocaine each produced significant increases from baseline ratings on all of the ARCI scales (Table 2, columns 1 and 3), there were no significant differences between effects of nalbuphine alone and in combination with cocaine (Table 2, column 5). Increases on PCAG, MBG, and amphetamine scales produced by nalbuphine + cocaine in combination were significantly higher than those produced by cocaine alone (Table 2, column 6). However, on the LSD scale, there were no significant differences between the effects of cocaine alone and in combination with nalbuphine (Table 2, column 6).

\section{Comparisons of the Subjective Effects of Cocaine Alone and in Combination with Nalbuphine (Figure 5)}

It was surprising to find that subjective effects ratings were usually higher after nalbuphine alone and nalbuphine + cocaine than after cocaine alone. Moreover, subjective effects ratings were equivalent after nalbuphine with and without cocaine, suggesting that the presence of cocaine did not produce additive effects. Figure 5 shows the results of subtracting VAS ratings for nalbuphine alone from ratings for nalbuphine + cocaine and comparing these with ratings for cocaine alone. This calculation assumes that the residual (nalbuphine + cocaine-nalbuphine alone) reflects the effects of cocaine when it was given in combination with nalbuphine. Peak VAS ratings for each of the stimulantrelated items were higher after administration of cocaine alone than the estimated contribution of cocaine to the subjective effects of nalbuphine + cocaine (Figure 5, top

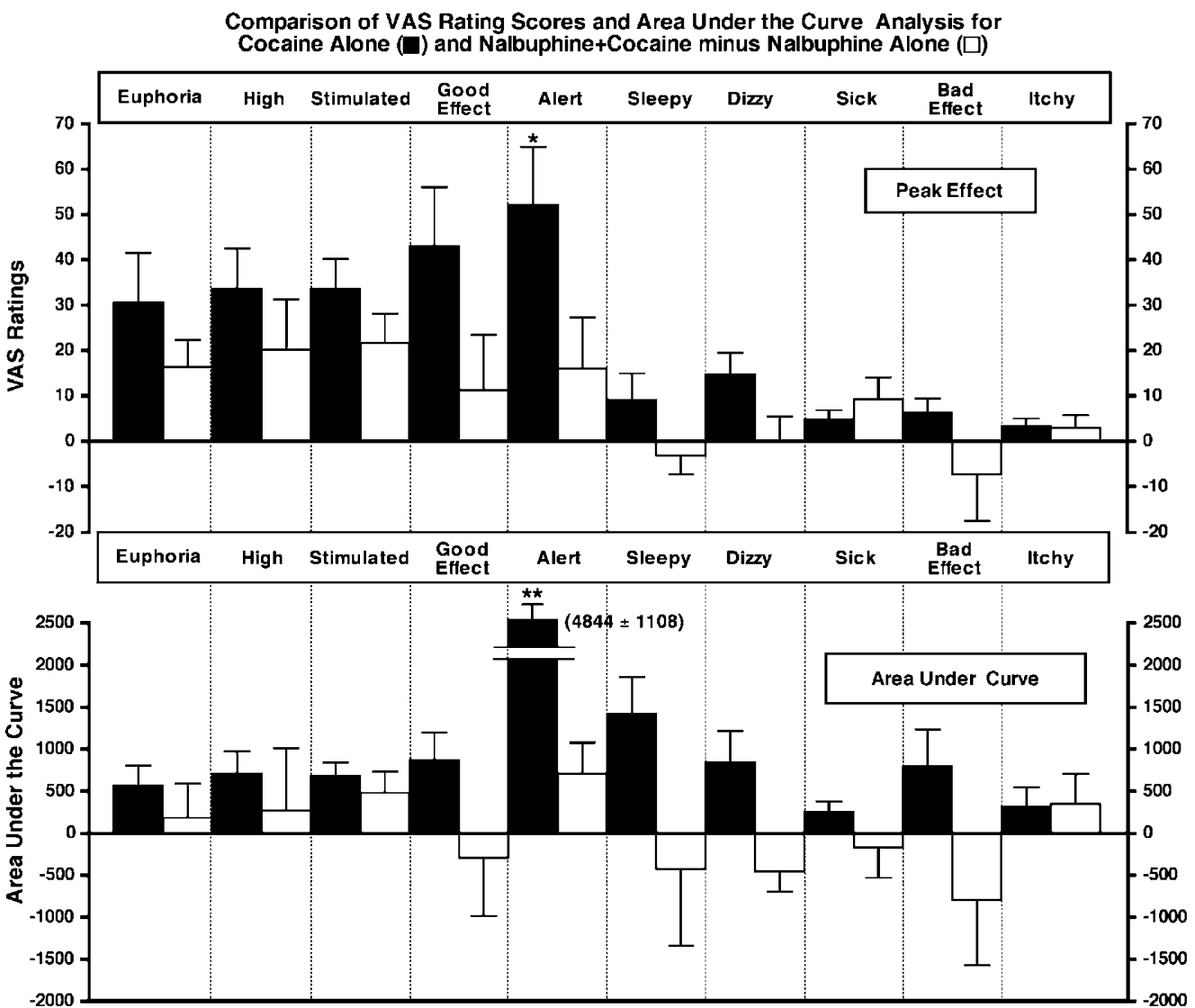

Figure 5 Comparison of VAS ratings after cocaine alone and nalbuphine + cocaine-nalbuphine alone. In all, I0 VAS items are shown at the top of each panel. Peak ratings for VAS items measured $5 \mathrm{~min}$ after cocaine administration ( $20 \mathrm{~min}$ post nalbuphine) are shown on the left ordinates (top panel). Peak VAS ratings $(\bar{x} \pm$ SEM) after cocaine alone are shown as filled rectangles. Open rectangles show peak VAS ratings for the same items calculated by subtracting peak ratings after nalbuphine alone from peak ratings after nalbuphine + cocaine (top panel). AUC values are shown on the left ordinate (bottom panel). AUC values for each VAS item after administration of cocaine alone are shown as filled rectangles. Open rectangles show AUC values for the same items calculated by subtracting AUC values after nalbuphine alone from AUC values after nalbuphine + cocaine. Each data point is the average $(\bar{x} \pm S E M)$ of seven subjects. 
panel, columns 1-5). The same pattern was observed when AUC was analyzed for the same VAS scores (Figure 5, bottom panel, columns 1-5). A similar pattern was observed for the opioid-related items Sleepy, Dizzy, and Bad Effect, but not for Sick and Itchy (Figure 5, columns 6-10). Adjective Checklist scores for stimulant- and opioid-related items were also higher after cocaine alone than after the estimated contribution of cocaine to the effects of nalbuphine + cocaine (data not shown).

\section{DISCUSSION}

This is the first clinical study to examine the interactions between nalbuphine, a mixed mu/kappa opioid agonist, and cocaine in male cocaine abusers. In preclinical studies, kappa opioids attenuated many of the abuse-related and locomotor-activating effects of cocaine, and these findings suggested that kappa opioids might be useful for the clinical treatment of cocaine abuse (Archer et al, 1996; see for a review Mello and Negus, 2000). Cocaine self-administration studies in non-human primates indicated that kappa opioids with mu receptor activity reduced cocaine selfadministration more effectively, and with fewer adverse side effects, than kappa selective opioids (Mello and Negus, 2000; Bowen et al, 2003). Accordingly, we chose nalbuphine from the very limited number of kappa opioids approved for clinical use by the FDA. Nalbuphine is classified as a kappa agonist/partial $\mathrm{mu}$ antagonist analgesic in the Physicians Desk Reference (PDR, 2003), and has a complex pharmacological profile (Schmidt et al, 1985; De Souza et al, 1988; Jaffe and Martin, 1990; Preston and Jasinski, 1991). Nalbuphine precipitated withdrawal in both morphine- and methadone-dependent subjects, and did not reduce abstinence signs and symptoms in opioid-dependent subjects during withdrawal from morphine maintenance (Preston and Jasinski, 1991).

One major finding of this study was that a $5 \mathrm{mg} / 70 \mathrm{~kg}$ dose of nalbuphine was safe and well tolerated when administered in combination with cocaine. There was no evidence of synergistic effects and, in general, the cardiovascular effects of the nalbuphine + cocaine combination were less than the effects of cocaine alone. Moreover, plasma/serum levels of cocaine and nalbuphine were equivalent when each drug was given alone and in combination. A second major finding was that the effects of nalbuphine + cocaine were not additive. Ratings of positive subjective effects after nalbuphine alone and nalbuphine + cocaine did not differ significantly, and both were greater than after administration of cocaine alone. The relation of these findings to previous clinical and preclinical studies of opioid-cocaine interactions are described below. The implications of these results for agonist medication approaches to therapy, and some limitations of this study are discussed.

\section{Nalbuphine and Cocaine Levels}

Peak levels of nalbuphine in serum were detected at $10 \mathrm{~min}$ after i.v. administration and 5 min before cocaine administration, indicating that high levels of nalbuphine were present at the time of cocaine administration. Peak levels of cocaine in plasma were detected 4 min after i.v. administration, and peak levels were equivalent when cocaine was administered alone and after nalbuphine (131 and $130 \mathrm{ng} /$ $\mathrm{ml})$. The half-life $\left(t_{1 / 2}\right)$ of cocaine in plasma also did not differ significantly after administration of cocaine alone and nalbuphine + cocaine. The plasma cocaine levels in the present study were similar to those measured after administration of $32 \mathrm{mg} / 70 \mathrm{~kg}$ cocaine in a study of cocaine and morphine interactions (Foltin and Fischman, 1992).

\section{Cardiovascular Effects of Nalbuphine, Cocaine, and Nalbuphine + Cocaine in Combination}

Nalbuphine. There were no significant changes in heart rate and systolic blood pressure following nalbuphine alone, and this is consistent with previous clinical studies. For example, when nalbuphine was given to healthy volunteers in a dose range of $2.5-10 \mathrm{mg} / 70 \mathrm{~kg}$, it did not affect systolic or diastolic blood pressure, or heart rate (Zacny et al, 1997). In the present study, nalbuphine produced significant decreases in diastolic blood pressure at 75 and $105 \mathrm{~min}$. These decreases in diastolic blood pressure may reflect sedation, because subjects reported feeling Sleepy, Drunk, and Spaced-Out after nalbuphine administration.

Cocaine alone and in combination with nalbuphine. The cardiovascular effects of cocaine alone were consistent with findings from several clinical laboratory studies (Foltin and Fischman, 1992; Foltin et al, 1995; Abreu et al, 2001; Walsh et al, 2001a). The combined administration of nalbuphine + cocaine did not significantly alter heart rate and systolic blood pressure in comparison to cocaine alone, and this is in agreement with a study of cocaine and hydromorphone combinations (Walsh et al, 1996). When cocaine was given in combination with hydromorphone, increases in heart rate and pressor effects were slightly greater than after cocaine alone, but the observed differences were not statistically significant (Walsh et al, 1996). However, when morphine was given in combination with cocaine, the cardiovascular effects of some dose combinations were significantly greater than the cardiovascular effects of cocaine alone (Foltin and Fischman, 1992). The increases in cardiovascular measures produced by the morphine + cocaine combination were less than predicted by an addition model of drug interaction (Foltin and Fischman, 1992).

\section{Subjective Effects of Nalbuphine, Cocaine, and Nalbuphine + Cocaine in Combination}

Nalbuphine and cocaine alone. Both cocaine and nalbuphine produced significant increases in the VAS and Subject-Rated Adjective Checklist items and ARCI subscale scores in comparison to baseline ratings. The time course and magnitude of increases the VAS and Adjective Checklist measures of positive subjective effects after cocaine and nalbuphine alone was similar to that reported in other clinical laboratory studies (Foltin and Fischman, 1992; Walsh et al, 1996; Zacny et al, 1997). The sedative effects of nalbuphine were also similar in time course and magnitude to those of the same dose of i.v. nalbuphine administered to normal volunteers (Zacny et al, 1997). Moreover, the VAS 
scores for Euphoria, High, Stimulated, and Good Effect were significantly higher after nalbuphine alone than after cocaine alone. These findings are similar to previous studies in which morphine $(10 \mathrm{mg} / 70 \mathrm{~kg})$ produced greater subjective effects then $16 \mathrm{mg} / 70 \mathrm{~kg}$ cocaine (Foltin and Fischman, 1992). The opioid-related VAS items, Sleepy and Dizzy, were also significantly higher after nalbuphine than after cocaine. However, the profile of responses on the ARCI subscales differed in that nalbuphine alone increased all ARCI scale scores in these cocaine abusers, but nalbuphine significantly decreased scores on the BG scale in drug-naïve volunteers (Zacny et al, 1997).

Nalbuphine + cocaine in combination. It was surprising to find that the positive subjective effects of nalbuphine alone usually were not significantly different from the effects of nalbuphine + cocaine. This finding is not consistent with reports that cocaine often appears to enhance the effects of opioids. Rather, the subjective responses to nalbuphine + cocaine appeared to be accounted for primarily by nalbuphine, and there was no evidence that the interactions between cocaine and nalbuphine were additive. The contribution of cocaine to the nalbuphine + cocaine combination was estimated by subtracting the average subjective effects of nalbuphine alone from the average subjective effects of nalbuphine + cocaine. Analysis of peak responses, measured $5 \mathrm{~min}$ after cocaine, and the AUC indicated that the estimated positive subjective effects of cocaine after administration of the nalbuphine + cocaine combination were less than after cocaine alone. This suggests that nalbuphine may have slightly attenuated the subjective effects of cocaine. This interpretation is consistent with our preclinical findings that chronic administration of mixed mu/kappa opioids selectively reduced cocaine self-administration as described below.

\section{Kappa Opioid-Cocaine Interactions}

We are aware of only one other clinical laboratory study that has examined the interactions between cocaine and kappa selective or mixed mu/kappa opioids (Walsh et al, 2001a). That study examined the acute effects of an arylacetamide kappa selective agonist, enadoline (20, 40, and $80 \mu \mathrm{g} / 70 \mathrm{~kg}$, intramuscular (i.m.)), and a mixed mu/ kappa agonist, butorphanol $(1.5,3$, and $6 \mathrm{mg} / 70 \mathrm{~kg}$, i.m.), on subjective and physiological responses to cocaine ( 20 and $40 \mathrm{mg}$, i.v.). Choice between cocaine and money was also evaluated in a self-administration procedure. As in the present study, cocaine alone increased VAS ratings of High, Liking, Good Effects, and Drug Effects (Walsh et al, 2001a). However, butorphanol did not enhance or decrease VAS ratings of cocaine's positive subjective effects, whereas enadoline tended to decrease VAS responses to cocaine (Walsh et al, 2001a). In the present study, scores on all the ARCI subscales increased significantly at some time point after nalbuphine, cocaine, and nalbuphine + cocaine administration. In contrast, both butorphanol + cocaine and enadoline + cocaine increased ARCI ratings on the LSD (dysphoria) scale and the PCAG scale (sedation), but had no significant effects on the morphine-benzedrine, amphetamine, or euphoria scales (Walsh et al, 2001a). Neither butorphanol nor enadoline significantly decreased choices of cocaine over money (Walsh et al, 2001a). The authors concluded that acute administration of butorphanol or enadoline did not substantially modify the subjective effects of cocaine or cocaine self-administration (Walsh et al, 2001a).

In contrast, in rhesus monkeys, chronic treatment with nalbuphine $(0.1 \mathrm{mg} / \mathrm{kg} / \mathrm{h}$ or 1.0 or $3.0 \mathrm{mg} / \mathrm{kg} /$ day $)$, as well as several other mixed mu/kappa opioids, significantly reduced cocaine self-administration over 7 to 10 days (Mello et al, 1993; Negus et al, 1997; Mello and Negus, 1998b; Negus and Mello, 2002; Bowen et al, 2003). The acute effects of mixed mu/kappa agonists on cocaine's reinforcing and discriminative stimulus effects have been less consistent. In a drug self-administration procedure where treatment drug effects on multiple unit doses of cocaine could be evaluated in two or three sessions (Caine et al, 2000), the mixed mu/ kappa agonists (-)cyclorphan, Mr2034, and MCL-101 dose dependently decreased cocaine self-administration with minimal side effects (Bowen et al, 2003). However, acute administration of the same mixed mu/kappa agonists that reduced cocaine self-administration did not significantly attenuate cocaine discrimination, and did not produce rightward shifts in the cocaine discrimination dose-effect curve in rhesus monkeys (Negus and Mello, 1999; Bowen et al, 2003).

\section{Mu Opioid-Cocaine Interactions}

Although subjective responses to nalbuphine and nalbuphine + cocaine were equivalent, the significantly higher ratings of positive drug effects after nalbuphine + cocaine in comparison to cocaine alone is consistent with several clinical laboratory studies of cocaine-opioid interactions. Both acute and chronic treatment with mu opioid agonists produced an enhancement of some abuse-related subjective effects of cocaine in humans (Preston et al, 1989; Foltin and Fischman, 1992; Strain et al, 1994; Foltin et al, 1995; Walsh et al, 2001a). For example, chronic methadone maintenance $(50 \mathrm{mg} /$ day, p.o.) enhanced the abuse-related subjective effects, (Liking, Good Effect, Rush) and physiological effects of i.v. cocaine $(12.5,25$ and $50 \mathrm{mg}$ ) in comparison to placebo-cocaine (Preston et al, 1996). Chronic maintenance on high methadone doses ( $70-80$ and $90-100 \mathrm{mg}$ /day, p.o.) enhanced subjective responses (Stimulated, Liking, Quality, Good Drug) to i.v. cocaine (8 or $16 \mathrm{mg} / 70 \mathrm{~kg}$ ) in comparison to maintenance on low methadone doses $(20-60 \mathrm{mg} /$ day, p.o.) (Foltin et al, 1995).

When an acute dose of morphine or hydromorphone was combined with i.v. cocaine administration, the ratings of positive subjective effects were usually higher than after either cocaine or the opioid alone (Foltin and Fischman, 1992; Walsh et al, 1996). For example, combinations of $20 \mathrm{mg}$ cocaine $+1.5 \mathrm{mg}$ hydromorphone or $40 \mathrm{mg}$ cocaine + $3.0 \mathrm{mg}$ hydromorphone produced higher VAS ratings than either drug alone, but these differences were not statistically significant (Walsh et al, 1996). On an Adjective Rating Scale, a number of subjective effects typical of cocaine (Stimulated, Excited) and opioid effects (Nodding, Itchy, Talkative) were significantly greater after cocaine + hydromorphone in combination than after either drug alone (Walsh et al, 1996). When morphine $(0,5$, and $10 \mathrm{mg} / 70 \mathrm{~kg}$ ) was given in combination with cocaine $(0,8,16$, and $32 \mathrm{mg} /$ 
$70 \mathrm{~kg}$ ), positive subjective effects (High, Liking) were significantly greater than for either drug alone (Foltin and Fischman, 1992). The authors emphasized that the increases in subjective effects ratings after cocaine $(32 \mathrm{mg})$ and morphine $(5 \mathrm{mg})$ in combination were less than would be predicted by an effect-addition model of drug interaction (Foltin and Fischman, 1992).

There is also evidence from preclinical studies that $\mathrm{mu}$ opioids may increase the abuse-related effects of cocaine. For example, opioid administration usually increases the discriminative stimulus effects of cocaine in squirrel monkeys (Spealman et al, 1992; Spealman and Bergman, 1994; Rowlett et al, 1998) and in rhesus monkeys (Mello et al, 1995; Negus et al, 1998; Negus and Mello, 2002). Cocaine and heroin may also enhance each other's reinforcing and discriminative stimulus effects when administered in a speedball (Rowlett and Woolverton, 1997; Negus et al, 1998). Speedball combinations of cocaine and heroin produce robust reinforcing and discriminative stimulus effects in rats and rhesus monkeys (Mello et al, 1995; Hemby et al, 1996, 1999; Rowlett and Woolverton, 1997; Mello and Negus, 1998a; Negus et al, 1998; Rowlett et al, 1998). Moreover, neurochemical findings suggest that self-administration of cocaine and heroin in combination has synergistic effects on extracellular dopamine release at the nucleus accumbens in rats in comparison to heroin or cocaine alone (Hemby et al, 1999).

\section{Limitations of the Study}

This is the first study of the effects of a combination of nalbuphine + cocaine in man. Subject safety considerations limited the doses of each drug administered. As $10 \mathrm{mg}$ i.v. nalbuphine produced nausea and vomiting in three subjects, we studied a lower dose of $5 \mathrm{mg}$ i.v. nalbuphine that was well tolerated by all subjects. Another limitation of this study is that only a single acute dose of nalbuphine + cocaine was evaluated. Whether or not chronic nalbuphine administration would have produced sustained alterations in cocaine's abuse-related subjective effects remains to be determined. Another issue that is not unique to this study, but affects all evaluations of drug combinations, is the difficulty inherent in estimating the relative contribution of each component drug to the observed effects. It could be argued that nalbuphine's long duration of action in comparison to cocaine contributed to the differences in the AUC results, even though plasma levels for both drugs had a similar half-life. For this reason, we analyzed both the AUC and peak effects $5 \mathrm{~min}$ after cocaine, and found similar profiles of subjective effects. Finally, although the number of subjects that completed the study was relatively small, each subject was studied under all drug conditions. This own control design is a significant strength of the study.

\section{Conclusions}

We conclude that under the conditions of this experiment, a combination of nalbuphine and cocaine was safe and did not produce synergistic cardiovascular effects. Moreover, the addition of cocaine did not significantly increase the subjective effects of nalbuphine. Rather, subjective responses to nalbuphine + cocaine were usually equivalent to responses to nalbuphine alone. These findings suggest that acute administration of nalbuphine may produce a modest attenuation of cocaine's abuse-related effects. Further studies of the effects of chronic nalbuphine treatment on the physiological and subjective effects of cocaine are warranted.

\section{ACKNOWLEDGEMENTS}

This research was supported by Grants P01-DA14528, U19DA11007, K05-DA00101 (NKM), K05-DA00064 and T32DA07252 (JHM) from the National Institute on Drug Abuse, National Institutes of Health. Preliminary data were reported to the College on Problems of Drug Dependence in 2003. We thank Alicja Skupny and Yonghong Cheng for performing the nalbuphine and cocaine assays and Inge Knudson for assistance with data analysis and for preparing the graphic displays.

\section{REFERENCES}

Abreu ME, Bigelow GE, Fleisher L, Walsh SL (2001). Effect of intravenous injection speed on responses to cocaine and hydromorphone in humans. Psychopharmacology 154: 76-84.

Abusada GM, Abukhalaf IK, Alford DD, Vinzon-Bautista I, Pramanik AK, Ansari NA et al (1993). Solid-phase extraction and GC/MS quantitation of cocaine, ecgonine methyl ester, benzoylecgonine, and cocaethylene from meconium, whole blood, and plasma. J Anal Toxicol 17: 353-358.

Archer S, Glick SD, Bidlack J (1996). Cyclazocine revisited. Neurochem Res 21: 1369-1373.

Bergman J, France CP, Holzman SG, Katz JL, Koek W, Stephens DN (2000). Agonist efficacy, drug dependence, and medications development: preclinical evaluation of opioid, dopaminergic, and GABA-ergic ligands. Psychopharmacology 153: 67-84.

Bowen CA, Negus SS, Zong R, Neumeyer JL, Bidlack JM, Mello NK (2003). Effects of mixed-action kappa-mu opioids on cocaine self-administration and cocaine discrimination by rhesus monkeys. Neuropsychopharmacology 28: 1125-1139.

Caine SB, Negus SS, Mello NK (2000). Effects of dopamine D1-like and D2-like agonists on cocaine self-administration in rhesus monkeys: rapid assessment of cocaine dose-effect functions. Psychopharmacology 148: 41-51.

Carroll FI, Howell LL, Kuhar MJ (1999). Pharmacotherapies for treatment of cocaine abuse, preclinical aspects. J Med Chem 42: 2721-2736.

Crawford CA, McDougall SA, Bolanos CA, Hall S, Berger SP (1995). The effects of the kappa agonist U-50,488 on cocaine-induced conditioned and unconditioned behaviors and Fos immuoreactivity. Psychopharmacology 120: 392-399.

De Souza EB, Schmidt WK, Kuhar MJ (1988). Nalbuphine: an autoradiographic opioid receptor binding profile in the central nervous system of an agonist/antagonist analgesic. J Pharmacol Exp Ther 244: 391-402.

Devine DP, Leone P, Pocock D, Wise RA (1993). Differential involvement of ventral tegmental $\mathrm{mu}$, delta and kappa opioid receptors in modulation of basal mesolimbic dopamine release: in vivo microdialysis studies. J Pharmacol Exp Ther 266: 1236-1246.

Di Chiara G, Imperato A (1988). Opposite effects of mu and kappa opiate agonists on dopamine release in the nucleus accumbens and in the dorsal caudate of freely moving rats. J Pharmacol Exp Ther 244: 1067-1080.

Evans SM, Cone EJ, Henningfield JE (1996). Arterial and venous cocaine plasma concentrations in humans: relationship to route 
of administration, cardiovascular effects and subjective effects. J Pharmacol Exp Ther 279: 1345-1356.

Foltin RW, Christiansen I, Levin FR, Fischman MW (1995). Effects of single and multiple intravenous cocaine injections in humans maintained on methadone. J Pharmacol Exp Ther 275: 38-47.

Foltin RW, Fischman MW (1991). Assessment of abuse liability of stimulant drugs in humans: a methodological survey. Drug Alcohol Depend 28: 3-48.

Foltin RW, Fischman MW (1992). The cardiovascular and subjective effects of intravenous cocaine and morphine combinations in humans. J Pharmacol Exp Ther 261: 623-632.

Glick SD, Maisonneuve IM, Raucci J, Archer S (1995). Kappa opioid inhibition of morphine and cocaine self-administration in rats. Brain Res 681: 147-152.

Hemby SE, Co C, Dworkin SI, Smith JE (1999). Synergistic elevations in nucleus accumbens extracellular dopamine concentrations during self-administration of cocaine/heroin combinations (Speedball) in rats. J Pharmacol Exp Ther 288: 274-280.

Hemby SE, Smith JE, Dworkin SI (1996). The effects of eticlopride and naltrexone on responding maintained by food, cocaine, heroin and cocaine/heroin combinations in rats. J Pharmacol Exp Ther 277: 1247-1258.

Howell LL, Wilcox KM (2001). The dopamine transporter and cocaine medication development: drug self-admnistration in nonhuman primates. J Pharmacol Exp Ther 298: 1-6.

Jaffe JH, Martin WR (1990). Opioid analgesics and antagonists. In: Gilman AG, Rall TW, Nies AS, Taylor P (eds). The Pharmacological Basis of Therapeutics. Pergamon Press: New York. pp 485-521.

Kaufman MJ, Levin JM, Ross MH, Lange N, Rose SL, Kukes TJ et al (1998). Cocaine-induced cerebral vasoconstriction detected in humans with magnetic resonance angiography. JAMA 279: 376-380.

Kuhar MJ, Ritz MC, Boja JW (1991). The dopamine hypothesis of the reinforcing properties of cocaine. Trends Neurosci 14: 299-302.

Kuzmin AV, Semenova S, Gerrits MAFM, Zvartau EE, Van Ree JM (1997). Kappa-opioid receptor agonist U50,488 H modulates cocaine and morphine self-administration in drug-naive rats and mice. Eur J Pharmacol 321: 265-271.

Maisonneuve IM, Archer S, Glick SD (1994). U50,488 a $K$ opioid receptor agonist, attenuates cocaine-induced increases in extracellular dopamine in the nucleus accumbens of rats. Neurosci Lett 181: 57-60.

Mansour A, Fox CA, Meng F, Akil H, Watson SJ (1994). Kappa 1 receptor mRNA distribution in the rat CNS: comparison to kappa receptor binding and prodynorphin mRNA. Mol Cell Neurosci 5: 124-144.

Martin WR, Sloan JW, Sapira JD, Jasinski DR (1971). Physiologic, subjective, and behavioral effects of amphetamine, methamphetamine, ephedrine, phenmetrazine, and methylphenidate in man. Clin Pharmacol Ther 12: 245-258.

Mello NK, Kamien JB, Lukas SE, Drieze J, Mendelson JH (1993). The effects of nalbuphine and butorphanol treatment on cocaine and food self-administration by rhesus monkey. Neuropsychopharmacology 8: 45-55.

Mello NK, Negus SS (1996). Preclinical evaluation of pharmacotherapies for treatment of cocaine and opioid abuse using drug self-administration procedures. Neuropsychopharmacology 14: 375-424.

Mello NK, Negus SS (1998a). The effects of buprenorphine on selfadministration of cocaine and heroin 'Speedball' combinations and heroin alone by rhesus monkeys. J Pharmacol Exp Ther 285: 444-456.

Mello NK, Negus SS (1998b). Effects of kappa opioid agonists on cocaine- and food-maintained responding by rhesus monkeys. J Pharmacol Exp Ther 286: 812-824.
Mello NK, Negus SS (2000). Interactions between kappa opioid agonists and cocaine: Preclinical studies. In: Glick SD and Maisonneuve IM (eds). The Archer Conference on Drug Abuse: New Medications. New York Academy of Sciences: New York. pp 104-132.

Mello NK, Negus SS, Lukas SE, Mendelson JH, Sholar JW, Drieze J (1995). A primate model of polydrug abuse: Cocaine and heroin combinations. J Pharmacol Exp Ther 274: 1325-1337.

Mendelson JH, Mello NK (1996). Drug Therapy: Management of cocaine abuse and dependence. $N$ Engl J Med 334: 965-972.

Mendelson JH, Mello NK (2004). Cocaine and other commonly abused drugs. In: Braunwald E, Fauci AS, Kasper DL, Hauser SL, Longo DL and Jameson JL (eds). 16th Edition of Harrison's Principles of Internal Medicine. The McGraw-Hill Co.: New York. pp 2570-2573.

Mendelson JH, Mello NK, Sholar MB, Siegel AJ, Kaufman MJ, Levin JM et al (1999). Cocaine pharmacokinetics in men and in women during the follicular and luteal phase of the menstrual cycle. Neuropsychopharmacology 21: 294-303.

Mendelson JH, Mello NK, Sholar MB, Siegel AJ, Mutschler N, Halpern J (2002). Temporal concordance of cocaine effects on mood states and neuroendocrine hormones. Psychoneuroendocrinology 27: 71-82.

Mendelson JH, Sholar M, Mello NK, Teoh SK, Sholar JW (1998). Cocaine tolerance: Behavioral, cardiovascular, and neuroendocrine function in men. Neuropsychopharmacology 18: 263-271.

Mendelson JH, Sholar M, Siegel AJ, Mello NK (2001). Effects of cocaine on luteinizing hormone in women during the follicular and luteal phases of the menstrual cycle and in men.J Pharmacol Exp Ther 296: 972-979.

Meng F, Xie GX, Thompson RC, Mansour A, Goldstein A, Watson SJ et al (1993). Cloning and pharmacological characterization of a rat kappa opioid receptor. Proc Natl Acad Sci USA 90: 99549958.

Negus SS, Gatch MB, Mello NK (1998). Discriminative stimulus effects of a cocaine/heroin 'speedball' combination in rhesus monkeys. J Pharmacol Exp Ther 285: 1123-1136.

Negus SS, Mello NK (1999). Effects of kappa opioid agonists on the discriminative stimulus effects of cocaine in rhesus monkeys. Exp Clin Psychopharmacol 7: 307-317.

Negus SS, Mello NK (2002). Effects of $\mu$-opioid agonists on cocaine- and food-maintained responding and cocaine discrimination in rhesus monkeys: role of $\mu$-agonist efficacy. J Pharmacol Exp Ther 300: 111-1121.

Negus SS, Mello NK, Portoghese PS, Lin C-E (1997). Effects of kappa opioids on cocaine self-administration by rhesus monkeys. J Pharmacol Exp Ther 282: 44-55.

Novick DM, Haverkos HW, Teller DW (1997). The medically ill substance abuser. In: Lowinson JH, Ruiz P, Millman RB, Langrod JG (eds). Substance Abuse A Comprehensive Textbook, 3rd edn. Williams \& Wilkins: Baltimore, MD. pp 534-550.

PDR (ed) (2003). Physicians Desk Reference, 57th edn. Thomson PDR: Montvale, NJ.

Pfeiffer A, Branti V, Herz A, Emrich HM (1986). Psychotomimesis mediated by k opiate receptors. Science 233: 774-776.

Platt DM, Rowlett JK, Spealman RD (2002). Behavioral effects of cocaine and dopaminergic strategies for preclinical medication development. Psychopharmacology (Berl) 163: 265-282.

Preston KL, Bigelow GE (2000). Effects of agonist-antagonist opioids in humans trained in a hydromorphone/not hydromorphone discrimination. J Pharmacol Exp Ther 295: 114-124.

Preston KL, Bigelow GE, Liebson IA (1989). Antagonist effects of nalbuphine in opioid-dependent humans. J Pharmacol Exp Ther 248: 929-937.

Preston KL, Jasinski DR (1991). Abuse liability studies of opioid agonist-antagonists in humans. Drug Alcohol Depend 28: $49-82$. 
Preston KL, Sullivan JT, Strain EC, Bigelow GE (1996). Enhancement of cocaine's abuse liability in methadone maintenance patients. Psychopharmacology 123: 15-25.

Reece PA, Sedman AJ, Rose S, Wright DS, Dawkins R, Rajagopalan $R$ (1994). Diuretic effects, pharmacokinetics, and safety of a new centrally acting kappa-opioid agonist (CI-977) in humans. J Clin Pharmacol 34: 1126-1132.

Rowlett JK, Wilcox KM, Woolverton WL (1998). Self-administration of cocaine-heroin combinations by rhesus monkeys: antagonism by naltrexone. J Pharm Exp Ther 286: 61-69.

Rowlett JK, Woolverton WL (1997). Self-administration of cocaine and heroin combinations by rhesus monkeys responding under a progressive-ratio schedule. Psychopharmacology (Berl) 133: 363-371.

SAMHSA (2000). Substance Abuse and Mental Health Services Administration. Major Drugs of Abuse from the 2000 Drug Abuse Warning Network Report. US Department of Health and Human Services: Rockville, MD.

Schenk S, Partridge B, Shippenberg TS (2001). Effects of the kappa-opioid receptor agonist, U69,593, on the development of sensitization and on the maintenance of cocaine self-administration. Neuropsychopharmacology 24: 441-450.

Schmidt WK, Tam SW, Shotzberger GS, Smith Jr DH, Clark R, Vernier VG (1985). Nalbuphine. In: Schuster CR, Harris LS (eds). Mixed Agonist-Antagonist Analgesics, Drug Alcohol Depend. Elsevier Science Publishers: New York. pp 339-362.

Shippenberg TS, Chefer VI, Zapata A, Heidbreder CA (2001). Modulation of the behavioral and neurochemical effects of psychostimulants by $\kappa$-opioid receptor systems. In: QuinonesJenab V (ed). The Biological Basis of Cocaine Addiction. Annals of New York Academy of Sciences: New York. pp 50-73.

Sholar MB, Mendelson JH, Mello NK, Siegel AJ, Kaufman MJ, Levin JM et al (1998). Concurrent pharmacokinetic analysis of plasma cocaine and adrenocorticotropic hormone in men. J Clin Endocrinol Metab 83: 966-968.
Spangler R, Zhou Y, Maggos CE, Zlobin A, Ho A, Kreek MJ (1996). Dopamine antagonist and 'binge' cocaine effects on rat opioid and dopamine transporter mRNAs. Neuroreport 7: 2196-2200.

Spealman RD, Bergman J (1994). Opioid modulation of the discriminative stimulus effects of cocaine: comparison of $\mu$, $\kappa$ and $\partial$ agonists in squirrel monkeys discriminating low doses of cocaine. Behav Pharmacol 5: 21-31.

Spealman RD, Bergman J, Madras BK, Kamien JB, Melia KF (1992). Role of $D_{1}$ and $D_{2}$ dopamine receptors in the behavioral effects of cocaine. Neurochem Int 20: 147S-152S.

Strain EC, Stitzer ML, Liebson IA, Bigelow GE (1994). Buprenorphine versus methadone in the treatment of opioid-dependent cocaine users. Psychopharmacology 116: 401-406.

Svingos AL, Colago EE, Pickel VM (1999). Cellular sites for dynorphin activation of kappa-opioid receptors in the rat nucleus accumbens shell. J Neurosci 19: 1804-1813.

Walsh SL, Geter-Douglas B, Strain EC, Bigelow GE (2001a). Enadoline and butorphanol: evaluation of $\kappa$-agonists on cocaine pharmacodynamics and cocaine self-administration in humans. J Pharmacol Exp Ther 299: 147-158.

Walsh SL, Strain EC, Abreu ME, Bigelow GE (2001b). Enadoline, a selective kappa opioid agonist: comparison with butorphanol and hydromorphone in humans. Psychopharmacology 157: 151-162.

Walsh SL, Sullivan JT, Preston KL, Garner J (1996). The effects of naltrexone on response to i.v. cocaine, hydromorphone and their combination in humans. J Pharmacol Exp Ther 279: 524-538.

Yuferov V, Zhou Y, LaForge KS, Spangler R, Ho A, Kreek MJ (2001). Evaluation of guinea pig brain preprodynorphin mRNA expression and hypothalamic-pituitary-adrenal axis activity by 'binge' pattern cocaine administration. Brain Res Bull 55: 65-70.

Zacny JP, Conley K, Galinkin J (1997). Comparing the subjective, psychomotor and physiological effects of intravenous buprenorphine and morphine in healthy volunteers. J Pharmacol Exp Ther 282: 1187-1197. 